\title{
Capsular synovial metaplasia mimicking silicone leak of a breast prosthesis: a case report
}

\author{
Sarah Krishnanandan ${ }^{1}$, Ali Abbassian*2, Anup K Sharma ${ }^{3}$ and Giles Cunnick ${ }^{4}$
}

Address: ${ }^{1}$ SpR in Accidents and Emergency, Kingston Hospital, Kingston, Surrey, KT2 7QB, UK, ${ }^{2}$ SpR in Trauma and Orthopaedics, Mayday University Hospital, Croydon, CR7 7YE, UK, ${ }^{3}$ Department of Breast Surgery, St. George's Hospital, Tooting, London, SW17, UK and ${ }^{4}$ Wycombe General Hospital, Queen Alexandra Road, High Wycombe, Bucks, HP11 2TT, UK

Email: Sarah Krishnanandan - sarah.abbassian@gmail.com; Ali Abbassian* - aabbassian@gmail.com; Anup K Sharma - noopysharma@hotmail.com; Giles Cunnick - gcunnick@doctors.org.uk

* Corresponding author

Published: 15 August 2008

Journal of Medical Case Reports 2008, 2:277

Received: 23 January 2008

Accepted: 15 August 2008

This article is available from: http://www.jmedicalcasereports.com/content/2/1/277

(c) 2008 Krishnanandan et al; licensee BioMed Central Ltd.

This is an Open Access article distributed under the terms of the Creative Commons Attribution License (http://creativecommons.org/licenses/by/2.0), which permits unrestricted use, distribution, and reproduction in any medium, provided the original work is properly cited.

\begin{abstract}
Introduction: Synovial metaplasia around a prosthesis and in particular around silicone breast implants has been noted by various investigators, but has unknown clinical significance. We report on a patient where a large amount of synovial fluid mimicked rupture of an implant. We believe this to be an unusual clinical presentation of this phenomenon. Review of the English language literature failed to identify a comparable case.
\end{abstract}

Case presentation: A 25-year-old woman had undergone bilateral breast augmentation for cosmetic reasons. One implant was subsequently subjected to two attempts at expansion to correct asymmetry. The patient was later found to have a large quantity of viscous fluid around the port of that same prosthesis. Histological assessment of the implant had consequently confirmed capsular synovial metaplasia. This had initially caused the suspicion of a silicone 'bleed' from the implant and had resulted in an unnecessary explantation.

Conclusion: Capsular synovial metaplasia should be ruled out before the removal of breast implants where a leak is suspected. Manipulation and expansion of an implant may be risk factors for the development of synovial metaplasia.

\section{Introduction}

Synovial metaplasia around prostheses is regarded as a transitional phenomenon [1]. We describe the case of a patient in whom, at the time of removal of a prosthetic port, the quantity of viscous fluid produced as a result of metaplasia caused us to suspect that a silicone bleed had occurred. This resulted in what later appeared to have been the unnecessary explantation of her implant.

\section{Case presentation}

A fit and healthy 25-year-old Caucasian woman presented with asymmetry and gross bilateral tubular deformity of the breasts. Subsequently, a bilateral breast reconstruction with $350 \mathrm{cc} \mathrm{Becker}^{\mathrm{TM}}$ (Mentor, UK) implants was performed. At the time of surgery, $200 \mathrm{ml}$ of saline was used to inflate both implants. The left implant was further inflated 1 and 5 months later using $80 \mathrm{ml}$ of normal saline on both occasions, to optimize symmetry. 
One year later, both ports were removed as a day case procedure. At that time, the right port was removed without complication. However, the left port was surrounded by a viscous fluid simulating implant rupture. A silicone gel bleed was suspected and another operation was planned where the left prosthesis was replaced with another permanent implant. The fluid and a sample of the periprosthetic capsule were sent for histological review. Histological examination revealed that the fluid was synovial fluid. The sample of capsule was found to be fibroadipose tissue, composed of fibrin-organizing histiocytes, lymphocytes and multinucleate giant cells. The capsule had undergone synovial metaplasia, which explained the presence of synovial fluid around the left implant. A typical histological appearance of synovial metaplasia is shown in Figure 1.

\section{Discussion}

Synovial metaplasia was first described by Brody and White [2] following their studies on implanted silicone joints in chickens. Another study of 85 patients with breast prostheses showed that the incidence of synovial metaplasia was $40 \%$ and that this condition was not as rare as had been previously suspected [1].
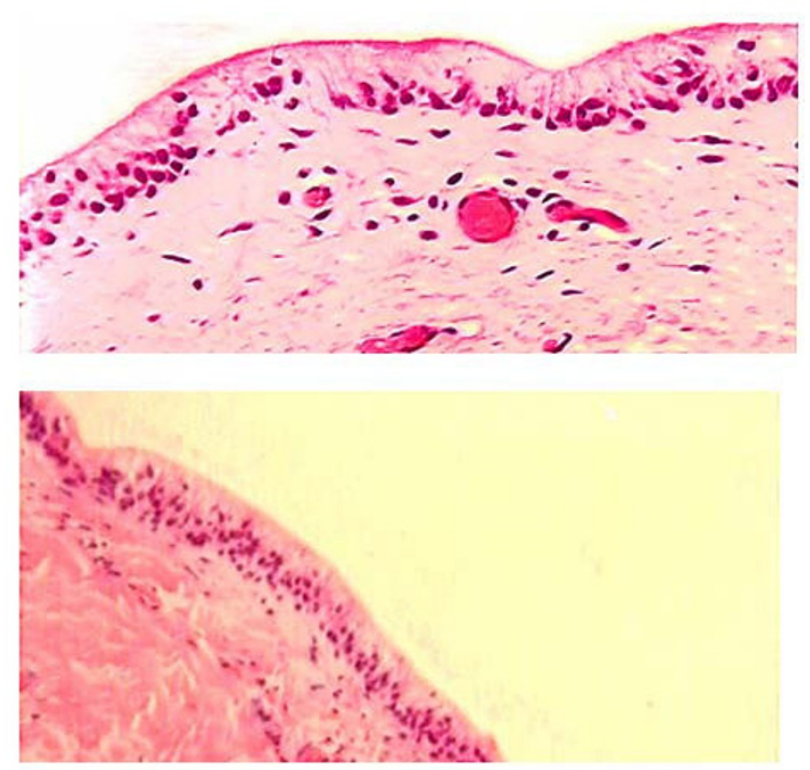

Figure I

Capsular synovial metaplasia. Sections from the cavity show the surface of the capsule lined by fibrohistiocytic cells. The nuclei of these cells are basally oriented and are polarized perpendicular to the cavity surface. The interface between the capsule and implant space is smooth. The overall features are indicative of synovial metaplasia.
A number of theories have been suggested to explain this phenomenon. One study suggested that the tissue reaction was a response to implants with a textured surface rather than a smooth surface [3]. In contrast, Ko et al. [1] suggested that the occurrence of synovial metaplasia did not correlate with the implant type. Instead they postulated that implant age may be a significant factor. The incidence had been shown to decrease with the age of the implant, suggesting that it may be a transitional finding in capsular maturation. This is in contrast to one report of synovial metaplasia that had presented with breast firmness and pain 26 years following implantation [4].

Another hypothesis suggests that mechanical stress may influence the development of synovial metaplasia. In one study [5], the bone-cement interface of loose hip prostheses, which is under considerable mechanical stress, was shown to undergo synovial metaplasia. Mechanical interference has also been associated with its development in the skin [6]. Mechanical stress may influence the development of synovial metaplasia in breast implants because of repeated surgery, expansion of the implants, the pendulous movement of the breasts or with chest wall muscle activity. Synovial metaplasia secretes lubricating factors and this may be beneficial for the reduction of capsular contracture. In one report, synovial metaplasia occurred after multiple manipulations and tissue expansions [7]. The investigators believed that this played an important role in the development of the metaplasia. The mechanical interference theory may explain the findings in our patient. The left prosthesis was expanded on two occasions, whereas the right prosthesis was not expanded at all. Synovial fluid was only macroscopically evident on the left side.

\section{Conclusion}

Silicone breast implants that are suspected of a leak should be assessed by histological examination of the fluid to rule out synovial metaplasia. This is particularly important if the implant has been subjected to expansions or manipulations. The clinical significance of synovial metaplasia is uncertain, however, increased awareness of this phenomenon by surgeons may reduce the unnecessary explantation of perfectly intact prostheses. If a leak is found to be due to synovial metaplasia, a period of observation and delay in explantation is advised as this may well be a transitional phenomenon.

\section{Consent}

Consent could not be obtained as the patient was untraceable. However, we believe the article contains a worthwhile clinical lesson which could not be made as effectively in any other way. The risk of identification of the patient is minimized by measures designed to prevent the identity of the patient being revealed either to others 
or to the patient's relatives. We expect the patient and their next of kin would not object to the publication of this case.

\section{Competing interests}

The authors declare that they have no competing interests.

\section{Authors' contributions}

SK and AA were involved in the literature search, writing up of the case and preparing the revision. AS and GC managed the clinical care of the patient as well as assisting in writing the manuscript.

\section{Acknowledgements}

We acknowledge the help and expertise of the histopathology department at St. George's Hospital and in particular Dr V. Thomas for the diagnosis and preparation of histological slides.

\section{References}

I. Ko CY, Ahn CY, Ko J, Chopra W, Shaw WW: Capsular synovial metaplasia as a common response to both textured and smooth implants. Plast Reconstr Surg 1996, 97: 1427-1432.

2. Brody GS, White WL: New concepts in prosthetic joints for use in the hand. Plast Reconstr Surg 1963, 32:45-58.

3. Copeland M, Choi M, Bleiweiss IJ: Silicone breakdown and capsular synovial metaplasia in textured-wall saline breast prostheses. Plast Reconstr Surg 1994, 94:628-633.

4. Kamel M, Fornasier VL, Peters W: Cartilaginous metaplasia in the capsule of a Dacron-based silicone gel prosthesis. Ann Plast Surg 1999, 42:202-206.

5. Goldring SR, Schiller AL, Roelke M, Rourke CM, O'Neil DA, Harris $\mathrm{WH}$ : The synovial-like membrane at the bone-cement interface in loose total hip replacements and its proposed role in bone lysis. J Bone Joint Surg Am 1983, 65(5):575-584.

6. Gonzalez JG, Ghiselli RW, Santa Cruz DJ: Synovial metaplasia of the skin. Am J Surg Pathol 1987, I I:343-350.

7. Raso DS, Greene WB, Metcalf JS: Synovial metaplasia of a periprosthetic breast capsule. Arch Pathol Lab Med 1994, I I 8:249-25I.
Publish with Bio Med Central and every scientist can read your work free of charge

"BioMed Central will be the most significant development for disseminating the results of biomedical research in our lifetime."

Sir Paul Nurse, Cancer Research UK

Your research papers will be:

- available free of charge to the entire biomedical community

- peer reviewed and published immediately upon acceptance

- cited in PubMed and archived on PubMed Central

- yours - you keep the copyright 